\title{
Neurocognitive models of aggression, the antisocial personality disorders, and psychopathy
}

\author{
R J R Blair
}

\begin{abstract}
This paper considers neurocognitive models of aggression and relates them to explanations of the antisocial personality disorders. Two forms of aggression are distinguished: reactive aggression elicited in response to frustration/threat and goal directed, instrumental aggression. It is argued that different forms of neurocognitive model are necessary to explain the emergence of these different forms of aggression. Impairments in executive emotional systems (the somatic marker system or the social response reversal system) are related to reactive aggression shown by patients with "acquired sociopathy" due to orbitofrontal cortex lesions. Impairment in the capacity to form associations between emotional unconditioned stimuli, particularly distress cues, and conditioned stimuli (the violence inhibition mechanism model) is related to the instrumental aggression shown by persons with developmental psychopathy. (F Neurol Neurosurg Psychiatry 2001;71:727-731)
\end{abstract}

Keywords: aggression; amygdala; orbitofrontal cortex

The goal of this paper is to consider neurocognitive models of aggression and relate these accounts to explanations of the antisocial personality disorders. However, firstly it is necessary to differentiate between the disorders conduct disorder (CD), antisocial personality disorder (APD), "acquired sociopathy" and psychopathy, and reactive and instrumental aggression.

Both CD and APD are DSM-IV diagnoses.

Institute of Cognitive Neuroscience and Department of Psychology, University College London, UK R J R Blair

Correspondence to: James Blair, Institute of Cognitive Neuroscience, 17 Queen Square, London WC1N 3AR, UK j.blair@ucl.ac.uk

Received 26 October 2001 and in revised form 2 May 2001

Accepted 2 July 2001 was introduced after the study of a patient who presented with profound emotional and behavioural changes after lesions to the ventromedial cortex. $^{2}$

Classifications of psychopathy are not synonymous with diagnoses of CD or APD but represent an extension. Psychopathy, in both childhood and adulthood, is currently defined with high scores on clinically based rating scales: for children, the psychopathy screening device $(\mathrm{PSD})^{3}$ and for adults, the revised psychopathy checklist (PCL). ${ }^{4}$ Factor analyses of behaviours rated on both the PSD and PCL disclose two independent factors: (1) an emotion dysfunction factor defined largely by emotional shallowness and lack of guilt and (2) an antisocial behaviour factor defined largely by instrumental aggression and the commission of a wide variety of offence types. ${ }^{5}{ }^{6}$ High scores on the antisocial behaviour factor of the PSD and PCL are closely associated with the diagnosis of CD and APD respectively. ${ }^{5}$ However, high scores on the emotion dysfunction factor, although highly correlated with scores on the antisocial behaviour factor, are less closely associated with the DSM diagnoses. More interestingly, scores on the emotion dysfunction factor seem to be determined, to a certain extent, by different influences from scores on the antisocial behaviour factor. Thus, both socioeconomic status and IQ are correlated with scores on the antisocial factor, but neither are associated with scores on the emotion dysfunction factor. ${ }^{6}$ Moreover, whereas scores on the antisocial behaviour factor decline with age, scores on the emotion dysfunction factor remain constant. ${ }^{7}$ This persistence suggests that the emotion dysfunction factor may more closely reflect the neurocognitive impairment(s) that are thought to result in the development of psychopathy.

The main reason for distinguishing these disorders is the high likelihood that there is no single explanation for all of them. Indeed, as regards CD and APD, there are strong suggestions that the diagnosed populations are highly heterogeneous. Thus, different risk factors are associated with life course persistent CD (appearing before the age of 10 years) and adolescence limited CD (appearing after 10 years).$^{8}$ In addition, there are considerable differences in the constellation of symptoms that different cases of CD and APD present with; 
importantly, some present with reactive and others with instrumental aggression. Reactive aggression is elicited in response to frustration/ threat while instrumental aggression is more purposeful and goal directed. ${ }^{9}$ Individuals with acquired sociopathy following orbitofrontal cortex lesions are a relatively homogeneous population; they present solely with reactive aggression even if the lesion occurs early in life. ${ }^{10}$ Psychopathic persons are also a relatively homogeneous population who present with a marked preponderance for instrumental antisocial behaviour including aggression. ${ }^{11}$

\section{The control of reactive aggression and "acquired sociopathy"}

Various models have been proposed that assume that there are executive systems that control reactive aggression. These can be crudely divided into the "inhibitory control" models ${ }^{1213}$ and the "executive emotional" models. ${ }^{214}$ In essence, the inhibitory control models suggest that violence in frontally impaired patients is due to the patients' inability to inhibit their violence impulses. ${ }^{12}{ }^{13}$ In line with these models, there is evidence that those with antisocial behaviour do show impaired performance on measures of executive functioning, including those of "inhibitory control" ${ }^{15}$ However, these models are underspecified at both the neural and cognitive levels. Little attempt has been made to specify which regions of frontal cortex might be involved, what the violent impulses are (or why they are activated), what stimuli activate the attempt to control the violent impulses in healthy persons and how the inhibitory control might be achieved. They could be considered redescriptions of the patient data. Moreover, it is difficult to meaningfully interpret reports that persons with antisocial behaviour show impaired performance on measures of executive functioning. ${ }^{15}$ If the measures index the functioning of systems involved in the control of violent impulses, then those who present with severely impaired performance on these measures should present with behavioural disturbance. Yet this is not always the case. Of course, the measures might just index the integrity of the frontal cortex and it is other systems mediated by the frontal cortex that inhibit violence impulses. But in this case, it is clear that the models are too underspecified to make precise predictions.

Before considering the executive emotion theories, it is necessary to make reference to the brain stem threat-response system, which when highly triggered, initiates a violent response. ${ }^{16} \mathrm{It}$ is triggered by increasing threat. At low levels of threat, this system, mediated by the hypothalamus and periaqueductal grey (PAG), ${ }^{16}$ initiates a freeze response. If the threat continues to approach, the system will initiate flight attempts. Finally, if flight is impossible, the system will initiate reactive aggression. Human reactive aggression may be conceptualised as a response to perceived threat that is mediated by this system. The amygdala feeds into this flight-fight response system information on the current state of threat in the environment and thus helps to determine whether the response is flight or fight. In addition, the orbitofrontal cortex has extensive projections to autonomic control centres in the medial hypothalamus and periaqueductal grey matter that are thought to mediate the flight-fight response. Interestingly, it is damage to the orbitofrontal cortex, rather than any other region of the frontal or posterior cortex, which places the patient at greatest risk of presenting with reactive aggression. ${ }^{17}$

How might the orbitofrontal cortex achieve the suppression of reactive aggression? Currently, two, not necessarily contrasting, executive emotion positions can be offered: the somatic marker hypothesis ${ }^{218}$ and the social response reversal hypothesis. ${ }^{14}$

THE SOMATIC MARKER MODEL

According to Damasio et al, the ventromedial frontal cortex (orbitofrontal and medial frontal cortex) acts as a repository, and is involved in the formation of recorded dispositional linkages between factual knowledge and bioregulatory states. ${ }^{218}$ When people are faced with a situation for which some factual aspects have been previously categorised, the dispositional linkages are activated. This can occur via a "body loop" in which a "somatic marker" is conveyed to somatosensory cortices, or via an "as-if body loop" in which the body is bypassed and reaction signals are conveyed to the somatosensory structures. Under either loop, the somatosensory structures then adopt an appropriate pattern that constrains option-outcome reasoning. In short, the somatosensory pattern marks the scenario as either good or bad, allowing the rapid rejection/ endorsement of specific option-outcome pairs. With regard to reactive aggression within this model, we could speculate that an option-outcome pair is activated such as "hit that person but be punished later". In a healthy person, there will be activation of the linkage between knowledge of hitting and punishment and the emotional aversion to punishment. The consequent aversive somatic marker should then guide the person away from hitting the other. However, if there is damage to the somatic marker system, there will be no somatic marker to guide behaviour. Certainly, those with "acquired sociopathy" are less likely to show autonomic responses to visually presented social stimuli (scenes of social disaster, mutilation, and nudity) at least under passive viewing conditions when they are not required to respond to the stimuli. ${ }^{18}$ In addition, such patients are less likely to shift their behaviour away from, and do not show, unlike controls, raised skin conductance responses on the four pack card playing task when they are choosing from packs of cards associated with high risk. ${ }^{18}$

THE SOCIAL RESPONSE REVERSAL MODEL

An alternative position makes reference to the role of the orbitofrontal cortex in response reversal as a consequence of changes in reinforcement contingencies. ${ }^{19}{ }^{20}$ However, this position stresses the role of social cues in 
modulating social behaviour. ${ }^{14}$ Angry expressions are known to curtail the behaviour of others in situations where social rules or expectations have been violated. ${ }^{21}$ Thus, it is suggested that there is a system that is activated by another's angry expressions and perhaps by representations of situations that have been previously associated with another person's angry responses or other negative valence expressions (for example, the staring expressions of others that can precede a sense of embarrassment and perhaps others' disgusted expressions) - that is, situations where another person's anger might be expected. The suggestion is that activation of this system results in the modulation of current behavioural responding, in particular the modulation of reactive aggression mediated by the hypothalamus and PAG (and perhaps sexual behaviour mediated by related systems). Evolutionarily, this system may have its origins in a system responsible for regulating behaviour in disputes between conspecifics at different levels in a social hierarchy. Decisions concerning whether to fight/flight a conspecific are heavily influenced by such cues as the other conspecifics' hierarchical location and whether they are currently displaying threat cues. ${ }^{22}$ In line with this position, neuroimaging findings have indeed shown the involvement of the right orbitofrontal cortex in processing angry, but not sad, facial expressions. ${ }^{23}$ Moreover, patients who present with reactive aggression after orbitofrontal cortex lesions have been found to be impaired in processing angry expressions and judging the appropriateness of behaviours in particular social contexts. ${ }^{14}$ In addition, both alcohol and diazepam have been found to selectively impair the ability of healthy persons to process angry expressions ${ }^{24}{ }^{25}$ and both are associated with increased risk for reactive aggression. ${ }^{26}$

The main difference between the social response reversal (SRR) and somatic marker positions is in the set of stimuli thought to activate both systems. For SRR, this is primarily angry expressions or the expectation of another's anger. By contrast, the somatic marker system is thought to be activated by a broad range of stimuli. The SRR position thus predicts that generating judgments on the basis of an expectation of another's anger should be dissociable from altering behaviour as a function of point rewards/ punishments on, for example, the four pack card playing task. Moreover, this seems to be the case. Thus, patients with acquired sociopathy have been found with SRR impairment but who show preserved performance on the four pack card playing task. ${ }^{14}$ In addition, adult developmental psychopaths showed no SRR impairment but have shown impairment on response reversal tasks. ${ }^{1425}$

Could either of the above explanations, either alone or in combination, account for all those with antisocial personality, including psychopathic persons? There have certainly been suggestions that early somatic marker impairment could result in developmental psychopathy. ${ }^{210}$ However, there are several difficulties with this position. Firstly, while persons with acquired sociopathy are generally autonomically hyporesponsive, psychopathic persons show selective hyporesponsiveness to sad and fearful expressions. ${ }^{27-30}$ Secondly, psychopathic persons have been found to be unimpaired on the four pack card playing task. ${ }^{31}$ In addition, whereas most antisocial behaviour committed by psychopathic persons is instrumental towards a goal (for example, increased respect), most antisocial behaviour committed by those with acquired sociopathy is a reactive consequence to frustration. ${ }^{32} 33$ In addition, as regards the social response reversal position, psychopathic people show appropriate responding to angry expressions. ${ }^{34}$ This is not to say that psychopathic persons may not present with orbitofrontal cortex dysfunction. Indeed, there are indications of impairment in psychopathic persons in response reversal after reinforcement contingency change, ${ }^{35}$ an impairment commonly seen in patients with orbitofrontal cortex damage. ${ }^{19}$ The argument is that the neurocognitive somatic marker and social response reversal positions, whatever their utility in accounting for acquired sociopathy, cannot provide an explanation for the instrumental aggression associated with developmental psychopathy.

\section{Instrumental aggression and developmental psychopathy}

There are two remarkable features of developmental psychopathy. Firstly, as noted above, the degree to which the antisocial behaviour of developmental psychopaths is instrumental. ${ }^{11}$ Secondly, the difficulty the caregiver faces in attempting to socialise an affected person. Indeed, psychopathy could be conceptualised as a disability that disrupts the socialisation process. For example, it has been shown that the use of negative parenting strategies by caregivers increases the probability of antisocial behaviour in children with CD who lack the emotional dysfunction of psychopathy. By contrast, the level of antisocial behaviour of children with CD who also present with the emotional dysfunction of psychopathy, is unrelated to the form of the parenting strategies adopted by their caregivers. ${ }^{36}$

The idea that psychopathy reflects dysfunction in the systems that allow socialisation is a well established one. ${ }^{37} 38$ Various positions have been proposed, almost all of which have suggested that the systems that mediate fear are dysfunctional in psychopathic persons. ${ }^{38-40}$ However, despite this variety, none of the positions has previously been able to account for the breadth of the data. For example, no satisfactory explanation have been put forward for why psychopathic persons show intact autonomic responses to basic threat stimuli, such as bared teeth displays, but not to threat stimuli produced through visual imagery. ${ }^{34}{ }^{41}$ Secondly, these positions have assumed that socialisation is achieved through fear conditioning. However, the developmental literature indicates that empathy induction - that is, reasoning that draws childrens' attention to the effects of their misdemeanours on others and increases 
empathy - rather than harsh, authoritarian or power assertive parenting practises are best for appropriate socialisation. ${ }^{42}$

THE VIOLENCE INHIBITION MECHANISM MODEL The importance of empathy for moral socialisation was one of the reason for the development of the violence inhibition mechanism model of psychopathy. ${ }^{34} 434$ This model was also prompted by work suggesting that most social animals possess mechanisms for the control of aggression. ${ }^{45} 46$ They noted that submission cues displayed to a conspecific aggressor terminate attacks - for example, an aggressor dog will cease fighting if its opponent bares its throat. The violence inhibition mechanism (VIM) is considered to be a functionally similar mechanism in humans where sad facial affects (distress cues) function as a human submission response. At its simplest, the VIM is thought to be a system that when activated by distress cues, the sad and fearful expressions of others, results in increased autonomic activity, attention and activation of the brain stem threat response system (usually resulting in freezing).$^{43}$ According to the model, moral socialisation occurs through the pairing of the activation of the mechanism by distress cues with representations of the acts which caused the distress cues (moral transgressions-for example, one person hitting another).$^{43}$ A process of classical conditioning results in these representations of moral transgressions becoming triggers for the mechanism. The appropriately developing child thus initially finds the pain of others' aversive and then, through socialisation, thoughts of acts that cause pain to others aversive also.

Blair has proposed that psychopathic persons have had disruption to this system such that representations of acts that cause harm to others do not become triggers for the VIM. ${ }^{43}$ This is thought to occur because the signal to the learning system concerning emotionally aversive stimuli is muted - that is, the unconditioned stimulus (US) signal is diminished, thus impairing the formation of US-conditioned stimulus (CS) associations. Certainly, the autonomic response of psychopathic persons to the aversive US of sad and fearful facial expressions is muted relative to controls. ${ }^{34}$ At the neural level, this has been attributed to dysfunction within the amygdala. ${ }^{23} 47$

As regards psychopathy, it is thought that the inability to form US (distress cues) - CS (representations of victim based transgressions) associations is the cause of the difficulty in their socialisation. ${ }^{43}$ But it is thought that other emotional USs are also muted. This is thought to be the cause of the impairments in psychopathic persons in aversive conditioning paradigms. ${ }^{48}$ In addition, disruption in the amygdala's ability to form US-CS associations would also impair the ability of the person to show augmentation of the startle reflex response after a visual threat prime. ${ }^{49}$ This impairment is also seen in psychopathic persons. ${ }^{40}$ The basic threat stimuli, bared teeth displays, that psychopathic persons do show arousal to, ${ }^{34} 40$ may activate autonomic activity through the social response reversal system or other non-amygdala based routes to the autonomic centres in the brain stem. However, threat stimuli produced through visual imagery rely on generating autonomic activity though US-CS associations that are reliant on the amygdala.

\section{Conclusion}

In conclusion, it is important to distinguish between reactive and instrumental aggression. These forms of aggression are associated with different disorders; "acquired sociopathy" after orbitofrontal cortex lesions and psychopathy after, perhaps, early amygdala dysfunction. Acquired sociopathy is most likely a consequence of disruption to the executive emotional systems that allow control over the brain stem systems that respond to threat. The instrumental antisocial behaviours shown by the developmental psychopath are a consequence of inability to socialise due to an impairment in the capacity to form associations between emotional unconditioned stimuli (particularly distress cues) and conditioned stimuli (specifically representations of transgressions). If the person is raised in a social environment (for example, poverty) where there are advantages for engaging in antisocial behaviour, they may engage in this behaviour but will not experience aversion to the distress of their victims. Because of the heterogeneity in the populations of those with CD and APD, different cases are likely to correspond to either a developmental form of acquired sociopathy (and some cases may reflect trauma) or developmental psychopathy itself.

This work was supported by the Medical Research Council (reference G9716841) and Department of Health (VISPED initiative)

\section{Addendum}

Could theory of mind be considered in the context of empathy and socialisation? Certainly, it has been argued that representations of the mental states of others are involved in the generation of empathic responses to the distress of others and in the control of agression. $^{50}$ Could psychopathy be due to theory of mind impairment? It seems not. Psychopathic persons show no theory of mind impairment. ${ }^{51}$ Moreover, children with autism do show autonomic, empathic responses to the distress of others even if they present with theory of mind impairment. ${ }^{52}$

1 American Psychiatric Association. Diagnostic and statistical manual of mental disorders. Washington, DC: American Psychiatric Association, 1994

2 Damasio AR. Descartes' error: emotion, rationality and the human brain. New York:Putnam (Grosset Books), 1994

3 Frick PJ, Hare RD. The psychopathy screening device. Toronto:Multi-Health Systems, 2001 (in press).

4 Hare RD. The Hare psychopathy checklist-revised. Toronto, Ontario: Multi-Health Systems, 1991.

5 Frick PJ, O'Brien BS, Wootton JM, et al. Psychopathy and conduct problems in children. F Abnorm Psychol 1994;103: 700-7.

6 Hare RD, Hart SD, Harpur TJ. Psychopathy and the DSM-IV criteria for antisocial personality disorder. $f$ Abnormal Psychol 1991;100:391-8.

7 Harpur TJ, Hare RD. Assessment of psychopathy as a function of age. F Abnorm Psychol 1994;103:604-9.

8 Moffitt TE. Adolescence-limited and life-course-persistent Moffitt TE. Adolescence-limited and life-course-persistent
antisocial behavior:a developmental taxonomy. Psychol Rev 1993;100:674-701. 
9 Berkowitz L. Aggression: its causes, consequences, and control. Philadelphia: Temple University Press, 1993.

10 Anderson SW, Bechara A, Damasio H, et al. Impairment of social and moral behaviour related to early damage in human prefrontal cortex. Nature Neuroscience 1999;2: 1032-7

11 Cornell DG, Warren J, Hawk G, et al. Psychopathy in instrumental and reactive violent offenders. $\mathcal{F}$ Consult Clin Psychol 1996;64:783-90.

12 Barratt ES. Impulsiveness and aggression. In:Monahan J, Steadman $\mathrm{H}$, eds. Violence and mental disorders:developments in risk assessment. Chicago: University of Chicago Press, 1994;61-79.

13 Krakowski M, Czobor P, Carpenter MD, et al. Community violence and inpatient assaults:Neurobiological deficits. $f$ Neuropsychiatry Clin Neurosci 1997;9:549-55.

14 Blair RJR, Cipolotti L. Impaired social response reversal:A case of "acquired sociopathy". Brain 2000;123:1122-41.

15 Morgan AB, Lilienfield SO. A meta-analytic review of the relation between antisocial behavior and neuropsychologirelation between antisocial behavior and neuropsychologi20:113-36.

16 Siegel A, Roeling TA, Gregg TR, Kruk MR. Neuropharmacology of brain-stimulation-evoked aggression. Neurosci Biobehav Rev 1999;23:359-89.

17 Grafman J, Schwab K, Warden D, et al. Frontal lobe injuries, violence, and aggression:A report of the Vietnam head injury study. Neurology 1996;46:1231-8.

18 Bechara A, Damasio H, Damasio AR. Emotion, decision making and the orbitofrontal cortex. Cereb Cortex 2000;10: 295-307.

19 Rolls ET. The orbitofrontal cortex. Phil Trans Roy Soc B 1997;351:1433-43.

20 Dias R, Robbins TW, Roberts AC. Dissociation in prefrontal cortex of affective and attentional shifts. Nature 1996;380:69-72.

21 Averill JR. Anger and aggression: an essay on emotion. New York: Springer-Verlag, 1982

22 de Waal FB. Coalitions as part of reciprocal relations in the Arnhem chimpanzee colony. In: Harcourt AH, de Waal Arnhem chimpanzee colony. In: Harcourt AH, de Waal FBM, eds. Coalitions and alliances in humans and other
mals. Oxford: Oxford University Press 1992:233-57.

23 Blair RJR, Morris JS, Frith CD, et al. Dissociable neural responses to facial expressions of sadness and anger. Brain 1999;122:883-93.

24 Blair RJR, Curran HV. Selective impairment in the recognition of anger induced by diazepam. Psychopharmacology 1999;147:335-8.

25 Borrill JA, Rosen BK, Summerfield AB. The influence of alcohol on judgement of facial expressions of emotion. $\mathrm{Br} f$ Med Psychol 1987;60:71-7.

26 Bond AJ, Curran HV, Bruce $M$, et al. Behavioural aggression in panic disorder after 8 weeks of treatment with alprazolam. F Affect Disord 1995;35:117-23.

27 Aniskiewicz AS. Autonomic components of vicarious conditioning and psychopathy. F Clinical Psychol 1979;35:60-7.

28 Blair RJR, Jones L, Clark F, et al. The psychopathic individual:A lack of responsiveness to distress cues? individual:A lack of responsiven

29 Patrick CJ, Bradley MM, Lang PJ. Emotion in the criminal psychopath:Startle reflex modulation. 7 Abnorm psychol psychopath:Startle

30 Damasio AR, Tranel D, Damasio HC. Somatic markers and the guidance of behavior:theory and preliminary testing.
In: Levin HS, Eisenberg HM, Benton AL, eds. Frontal lobe function and dysfunction. New York: Oxford University Press, 1991;217-29.

31 Schmitt WA, Brinkley CA, Newman JP. Testing Damasio's somatic marker hypothesis with psychopathic individuals: Risk takers or risk averse? f Abnorm Psychol 1999;108:53843.

32 Anderson SW, Bechara A, Damasio H, et al. Impairment of social and moral behaviour related to early damge in human prefrontal cortex. Nature Neuroscience 1999;2: human

33 Cornell DG, Warren J, Hamk G, et al. Psychopathy in instrumental and reactive violent offenders. $\mathcal{F}$ Consult Clin Psychol 1996;64:783-90.

34 Blair RJR, Jones L, Clark F, et al. The psychopathic individual:A lack of responsiveness to distress cues? Psychophysiology 1997;34:192-8.

35 LaPierre D, Braun CMJ, Hodgins S. Ventral frontal deficits in psychopathy:neuropsychological test findings. Neuropsychologia 1995;33:139-51.

36 Wootton JM, Frick PJ, Shelton KK, et al. Ineffective parenting and childhood conduct problems:The moderating role of callous-unemotional traits. Fournal of Consulting and Clinical Psychology. 1997;65:292-300.

37 Eysenck HJ. Crime and personality. London:Routledge and Kegan Paul, 1964.

38 Hare RD. Psychopathy:Theory and Research. New York: Wiley, 1970.

39 Gray JA. The Psychology of Fear and Stress. London: Weienfeld and Nicolson, 1971.

40 Patrick CJ. Emotion and psychopathy:startling new insights. Psychophysiology 1994;31:319-30.

41 Patrick CJ, Cuthbert BN, Lang PJ. Emotion in the criminal psychopath:fear image processing. F Abnorm Psychol 1994; 103:523-34

42 Baumrind D. Current patterns of parental authority. Developmental Psychology Monographs 1971;94:132-42.

43 Blair RJR. A cognitive developmental approach to morality: Investigating the psychopath. Cognition 1995;57:1-29.

44 Blair RJR, Morton J. Putting cognition into sociopathy. Brain and Behavioral Science 1995;18:548.

45 Eibl-Eibesfeldt I. Ethology: the biology of behaviour. New York: Holt, Rinehart and Winston, 1970.

46 Lorenz K. The foundation of ethology. New York: SpringerVerlag, 1981.

47 Blair RJR, Frith U. Neuro-cognitive explanations of the Antisocial Personality Disorders. Criminal Behaviour and Mental Health 2001 (in press).

48 Raine A. The psychopathology of crime. New York: Academic Press, 1997.

49 LeDoux J. The Emotional Brain. New York:Weidenfeld and Nicolson, 1998.

50 Feshbach ND. Parental empathy and child adjustment/ maladjustment. In:Eisenberg N, Strayer J, eds. Empathy and its development. New York: Cambridge University Press 1987.

51 Blair RJR, Sellars C, Strickland I, et al. Theory of Mind in the psychopath. Fournal of Forensic Psychiatry 1996;7:1525.

52 Blair RJR. Psychophysiological responsiveness to the distress of others in children with autism. Personality and Individual Differences 1999;26:477-85. 